\title{
Medical decision in COPD: the evidence-based history
}

António Duarte-de-Araújo, ${ }^{1-3}$ Miguel Guimarães, ${ }^{4}$ Pedro Teixeira, ${ }^{1-2}$ Venceslau Hespanhol, ${ }^{5-6}$ Jaime Correia-de-Sousa ${ }^{1-2,7}$

\begin{abstract}
Randomized controlled trials together with systematic reviews and meta-analyses have been the cornerstone of clinical research. Some studies, because of the size of the sample, the use of randomization and well-defined measurements, the participation of multiple institutions, or long-term follow-up, are able to give a significant level of evidence. We chronologically describe and comment on a group of trials on chronic obstructive pulmonary disease (COPD) that have significantly influenced the scientific and medical community in understanding and managing the disease in the first years of the XXI century. They contributed to the different versions of the GOLD strategy.
\end{abstract}

Keywords: COPD; Evidence; Randomized controlled trials; Treatment; Outcomes.

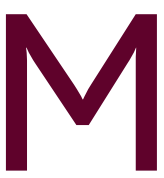
edicine intends to help patients. Medical decision and treatment choice must be based on the best scientific information currently available. Randomized controlled trials together with systematic reviews and meta-analyses have been the cornerstone of clinical research. ${ }^{1}$ The objective of clinical guidelines is to produce useful recommendations for clinicians, by searching, analyzing, and assessing the more relevant available scientific information. Some studies, because of the size of the sample, the use of randomization and well-defined measurements, the participation of multiple institutions, or long-term follow-up, are able to give a significant level of evidence. ${ }^{2}$ We chronologically describe and comment on a group of trials on COPD that have significantly influenced the scientific and medical community in understanding and managing the disease in the first years of the $21^{\text {st }}$ century.

In Europe, by the end of the $20^{\text {th }}$ century, both $\mathrm{FEV}_{1}$ and $\mathrm{FEV}_{1}$ decline were central measurements in the understanding of the disease. Extensive evidence showed

1. Life and Health Sciences Research Institute (ICVS), School of Medicine, University of Minho. Braga, Portugal.

2. ICVS/3B's, PT Government Associate Laboratory. Braga/Guimarães, Portugal.

3. Pneumologist. Respiratory Department, Hospital da Senhora da Oliveira. Guimarães, Portugal.

4. Pneumologist. Respiratory Department, Centro Hospitalar de Gaia/Espinho. Vila Nova de Gaia, Portugal.

5. Respiratory Department, Centro Hospitalar de S. João. Porto, Portugal.

6. Faculty of Medicine (FMUP), University of Porto. Porto, Portugal.

7. Family physician. Horizonte Family Health Unit. Matosinhos, Portugal. that patients could benefit from treatment, beyond smoking cessation, and oxygen for hypoxemic patients. Inhaled corticosteroids (ICS) were used to treat patients with COPD, and this empirical use seemed to be justified by the episodical increase in $\mathrm{FEV}_{1}$ and the reported decrease of $\mathrm{FEV}_{1}$ decline after treatment with oral corticosteroids. The Inhaled Steroids in Obstructive Lung Disease in Europe (ISOLDE) trial was published in 2000, and for the first time, health status was proven to decline over time in patients with moderate to severe COPD. ${ }^{3}$ In such patients, fluticasone propionate in high dosage ( $500 \mu \mathrm{g}$ twice daily) demonstrated to significantly reduce acute exacerbations and the rate of decline of health status, even if there was no benefit on the rate of $\mathrm{FEV}_{1}$ decline. A previous study, the European Respiratory Society Study on Chronic Obstructive Pulmonary Disease (EUROSCOP), ${ }^{4}$ published in 1999, had shown that the overall effect of three years of treatment with budesonide on $\mathrm{FEV}_{1}$ of smoking patients with mild COPD was small, and did not affect its long-term decline. Nonetheless, the ISOLDE study significantly encouraged the use of high doses of ICS in moderate to severe COPD patients in clinical practice.

At the beginning of the $21^{\text {st }}$ century, there was significant evidence that long-acting $\beta 2$ agonists (LABA) improved lung function, symptoms, and health status. There was also some evidence that fluticasone delayed the deterioration of health status and reduced the rate of exacerbations. However, the effect of the 
combination of the two drugs was not known and was tested for the first time in the TRISTAN study (2003). ${ }^{5}$ It showed that in patients with moderate to severe COPD, the combination therapy (ICS + LABA) was associated with better control of symptoms, reduction of exacerbations, and a modest effect on $\mathrm{FEV}_{1}$. The influence of these two trials, the ISOLD and the TRISTAN, established, at that time, the paradigm of the association of high doses of ICS together with a LABA in the treatment of moderate to severe COPD, which would last in clinical practice long after opposing evidence. After a nihilistic approach in the treatment of COPD,${ }^{4}$ an aggressively optimistic approach was adopted.

Brantigan et al., in 1959, first reported lung volume reduction surgery (LVRS), palliative treatment for severe emphysema. It was reintroduced in 1995 by Cooper et al. These authors described, in 1996, the effects of 150 consecutive bilateral lung volume reductions in patients with severe emphysema. However, there was a significant lack of criteria for patient selection. The National Emphysema Treatment Trial (NETT) identified high-risk patients that should be excluded from surgical procedure, and demonstrated a better survival, compared to medical therapy, in patients with both predominantly upper-lobe emphysema and low base-line exercise capacity, after pulmonary rehabilitation. ${ }^{6}$ This study, published in 2003, established the criteria currently used for the selection of COPD patients to LVRS. The effects were proven to be durable, with the improvement of exercise capacity and symptoms, respectively throughout a 3 and 4-year period. Interventional therapy has naturally evolved to video-assisted thoracoscopy and to bronchoscopy interventions. Currently, some patients may have a better quality of life after LVRS, acting as a bridge to transplantation or even without needing a transplant.

In the first years of the last decade, COPD was already understood as a complex and heterogeneous disorder. It was known that $\mathrm{FEV}_{1}$ did not capture the entire complexity of the disease. It did not fully correlate with other COPD outcomes, as the degree of dyspnea or the systemic manifestations, and both dyspnea and health status seemed to more accurately predict the risk of death. Different authors have investigated other predictive factors related to COPD mortality, like age, hypoxemia, co-morbidities, and exercise tolerance. Acu- te exacerbations of COPD (ECOPD) were recognized to have a relevant role in the natural history of the disease, but little was known about their direct influence on patient mortality. In 2004 Celli et al. proposed the BODE index (the Body-Mass, Airflow Obstruction, Dyspnea, and Exercise Capacity Index) to predict the risk of death, the more definitive outcome in COPD. ${ }^{7}$ That was the first multi-component tool described, and promised to be an important instrument in the careful assessment of patients. Multidimensional indices were a significant step forward to best describe the complexity of the disease.

In a prospective study of COPD patients followed for five years, Soler-Cataluña et al. demonstrated the importance of severe ECOPD on patient mortality. ${ }^{8}$ It became evident that mortality increased with the frequency of exacerbations, becoming ECOPD another prognostic factor, as $\mathrm{FEV}_{1}$, age, body mass index, comorbidity, or respiratory failure.

Smoking cessation in all patients, oxygen therapy for hypoxemic patients, and LVRT in selected patients, were the only therapeutic procedures proven to improve survival in COPD patients. Therefore, this study opened a new perspective in patients suffering from COPD, because medical treatments have proven to reduce the frequency of ECOPD. The importance given to ECOPD led to choosing exacerbations as a primary end-point in the evaluation of different pharmacological therapies in many clinical trials.

A reduction in mortality rate in patients treated with fluticasone was seen in a post hoc analysis of the ISOLDE study. It provided the rationale for a new study in which, for the first time, all-cause mortality in COPD patients was the primary outcome. It was necessary to alter the progressive course of COPD. The TORCH (Towards a Revolution in COPD Health) was published in $2007 .{ }^{9}$ It clarified, partially, the role of pharmacotherapy on COPD. Until then, the overall utility of ICS, although widely used in clinical practice, remained controversial in the scientific community. The clinical implications of the trial were that monotherapy with ICS should not be advocated, monotherapy with LABA was safe and useful, and the combination therapy decreased exacerbations, improved health status, offered protection against a decline in lung function, but did not affected all-cause mortality. 
Tiotropium was the first drug specifically designed for COPD patients. It was the first long-acting muscarinic antagonist (LAMA) to be commercialized, providing 24-hour improvements in $\mathrm{FEV}_{1}$ and hyperinflation. The UPLIFT (Understanding Potential Long-Term Impacts on Function) trial was published in $2008,{ }^{10}$ and was designed to test the hypothesis that the regular use of tiotropium could decrease the rate of $\mathrm{FEV}_{1}$ decline. The primary end-point was not reached, but it was associated with positive effects on health-related quality of life and a reduced risk of exacerbations and hospitalizations. The clinical implication was that tiotropium should be used to treat symptoms but not to alter the natural history of the disease.

As tiotropium, salmeterol, fluticasone and the association between the last two drugs have been shown to prevent ECOPD, a trial was designed to compare the efficacy of the combination therapy (ICS+LABA) versus tiotropium alone in preventing exacerbations, in severe and very severe COPD. The INSPIRE study, ${ }^{11}$ also published in 2008, found no difference in the overall rate of exacerbations between the two treatment groups.

An epidemiological study, ${ }^{12}$ the Evaluation of COPD Longitudinally to Identify Predictive Surrogate Endpoints (ECLIPSE), published in 2010, confirmed the previous evidence that exacerbations became more frequent as the severity of COPD increased. It was also clear, for the first time, that the most reliable predictor of ECOPD, in an individual patient, was a previous story of exacerbations. The ECLIPSE study also established the paradigm of the 'frequent-exacerbator' phenotype: independent of disease severity, stable over time, and easily identified on the basis of the previous history of exacerbations. Some patients are more prone to exacerbation not due to their functional severity but rather to an intrinsic personal susceptibility. This fact had important implications on the management of the disease. Agusti et al., analyzing data collected at recruitment of the ECLIPSE study, also accomplished relevant observations reflecting the heterogeneity of the disease. ${ }^{13}$ They were against the importance given to common COPD classification based upon the degree of airflow limitation because it was a poor predictor of other features of the disease.

By the year 2011, there was sufficient evidence to recommend the use of long-acting bronchodilators to treat symptoms and reduce the risk of exacerbations in patients with moderate, severe, and very severe COPD. However, there was no evidence regarding whether a LABA or a LAMA should be selected. In the POET-COPD study, patients with moderate to very severe COPD and a history of exacerbations were evaluated. Tiotropium was found more effective than salmeterol, significantly increasing the time to the first moderate or severe exacerbation, and significantly decreasing the annual rate of ECOPD. Although a considerable number of patients received concomitant therapy with ICS and the inhalation devices used to deliver salmeterol (a pMDI®) or tiotropium (the HandiHaler ${ }^{\circledR}$ ) were different, this was the first study to demonstrate the superiority of a LAMA over a LABA in the prevention of exacerbations. The main clinical implication was that a LAMA should be the first bronchodilator to be selected in symptomatic patients with a history of recent exacerbations. ${ }^{14}$

The SPARK study was the first to report the efficacy of dual long-acting bronchodilator therapy in patients with severe and very severe COPD and a high risk of exacerbations. ${ }^{15}$ At the time the trial was published, according to the GOLD 2013 strategy, the assessment of risk for COPD exacerbations was based both on the history of previous exacerbations and airflow limitation, and dual bronchodilator therapy was only the second-choice option, for both C and D categories. A combined bronchodilator therapy superiority was proven to prevent moderate to severe exacerbations, compared to a single LAMA therapy. The message for clinical practice was clear, and the strength was enough to suggest a revision in the treatment strategy for GOLD's C and D groups. However, the ICS+LABA association was the other first-choice therapeutic recommendation for the same GOLD categories, and it was never compared with dual bronchodilator therapy, until the publication of the FLAME study in $2016 .{ }^{16}$

There was significant evidence to recommend the association of an ICS+LABA to treat patients at risk of frequent exacerbations. ${ }^{15}$ Nonetheless, with the evidence of the superiority of the dual bronchodilator therapy over only one bronchodilator in preventing COPD exacerbations, the benefit of ICS, in addition to two bronchodilators, was not significantly explored. The Withdrawal of Inhaled Steroids During Optimized Bronchodilator Management (WISDOM) study was the first trial with sufficient strength to prove the 
hypothesis of therapeutic de-escalation in COPD. ${ }^{17}$ All patients were treated with tiotropium plus salmeterol. A stepwise reduction in fluticasone in one arm of the study did not increase the risk of moderate or severe exacerbations. The message for clinical practice was clear: the continuation of using ICS, in patients taking longacting bronchodilators, can only be justified if a symptomatic improvement may be attributable to the ICS.

For many years, since the seminal research by Fletcher and Peto, ${ }^{18}$ the natural course of the disease was seen as an acceleration of the natural age-related decline in lung function, assessed by $\mathrm{FEV}_{1}$, in susceptible persons to tobacco smoke or other noxious particles or gases. Using data from three large studies, the Framingham Offspring Cohort, the Copenhagen City Heart Study, and the Lovelace Smokers Cohort, Lange et al. found that the lung function reached early adulthood was related to the diagnosis of COPD later in life. In some patients there was a rapid decline in $\mathrm{FEV}_{1}$ from a normal level of lung function and others did not have accelerated rates of decline, started instead from a low initial value of $\mathrm{FEV}_{1}$. A wide range of individual trajectories, related to $\mathrm{FEV}_{1}$ decline was also found. Furthermore, periods of rapid decline and others with normal decline can co-exist in the same person. This study, published in 2015, emphasized the need for an early diagnosis of COPD, and drew attention to other risk factors, as maternal smoking and asthma or respiratory infections in childhood.

The FLAME study, in 2016, compared an ICS+LABA with a LAMA+LABA for the prevention of ECOPD of all severities. The rationale of the study reports to previous studies, namely the POET, the SPARK, and theWISDOM, and to the importance given to COPD exacerbations, a key feature in the natural history of the disease. The superiority of a LAMA+LABA combination versus an ICS+LABA combination was proved for the first time. The LAMA+LABA association was found to better improve lung function, quality of life and prevent exacerbations, no matter the baseline blood eosinophil count ( $2 \%$ or higher). This conclusion conflicts with other trials, showing increased rates of ECOPD among patients with a blood eosinophil count $\geq 4 \%$ or $300 \mathrm{cell} / \mu \mathrm{L}$.

In the same year, the Study to Understand Mortality and Morbidity in COPD (SUMMIT) found that fluticasone plus vilanterol therapy was safe and did not affect cardiovascular outcomes. It reduced exacerbations and the $\mathrm{FEV}_{1}$ decline but did not affect the overall mortality in patients with both moderate COPD and heightened cardiovascular risk. ${ }^{19}$

The role of ICS in the treatment of COPD continues to be the object of debate, and their role in step-up from dual (LAMA + LABA) to triple therapy has been weak. The IMPACT study, published in 2018, aimed to fill this gap, by comparing a once-daily triple therapy with dual therapy. ${ }^{20}$ Not surprisingly, triple therapy resulted in a lower rate of moderate or severe COPD exacerbations, a lower rate of hospitalizations, better lung function, and better related quality of life. The study also showed that combination therapy (ICS+LABA) was superior to double bronchodilator therapy, in preventing COPD exacerbations. This finding contrasts with the FLAME results. The inclusion of patients with a past history of asthma, and the withdrawal of ICS at randomization, in patients to whom they were recommended, could justify the different findings between the two studies. This can also suggest that only a subset of patients could in fact benefit from triple therapy. ${ }^{21}$ Meanwhile, when adding an ICS to double bronchodilator therapy, clinicians may expect a lower rate of ECOPD but a higher risk of pneumonia - which can be more acceptable is a matter to be decided on an individual basis.

\section{THE EVIDENCE-BASED MEDICAL DECISION IN COPD}

Evidence related to the treatment of patients with COPD is reflected in the GOLD strategy. Smoking cessation is mandatory in all patients. Long-term oxygen therapy improves survival in chronic hypoxemic patients. Pulmonary rehabilitation improves dyspnea, health status, and exercise tolerance. In selected patients with upper lobe emphysema refractory to medical care, surgical or bronchoscopy treatments have to be considered. Pharmacological therapy reduces symptoms, the frequency and severity of exacerbations, and improves health status and exercise tolerance. There is no conclusive evidence that current medications can stop the long-term decline in $\mathrm{FEV}_{1}$. Long-acting bronchodilators are central medication in this disease. In COPD patients without a previous history of asthma or features of asthma, ICS can be used in case of severe loss of lung function or frequent exacerbations, after optimization of bronchodilator treatment. 


\section{REFERENCES}

1. Shrimanker R, Beasley R, Kearns C. Letting the right one in: evaluating the generalizability of clinical trials. Eur Respir J. 2018;52(6):1802218.

2. Djulbegovic B, Guyatt $\mathrm{GH}$. Progress in evidence-based medicine: a quarter century on. Lancet. 2017;390(10092):415-23.

3. Burge PS, Calverley PM, Jones PW, Spencer S, Anderson JA, Maslen TK. Randomised, double blind, placebo controlled study of fluticasone proprionate in patients with moderate to severe chronic obstructive pulmonary disease: the ISOLD trial. BMJ. 2000;320(7245):1297-303.

4. Pauwels RA, Löfdahl CG, Laitinen LA, Schouten JP, Postma DS, Pride NB, et al. Long-term treatment with inhaled budesonide in persons with mild chronic obstructive pulmonary disease who continue smoking. N Engl J Med. 1999;340(25):1948-53.

5. Calverley P, Pauwels R, Vestbo J, Jones P, Pride N, Gulsvik A, et al. Combined salmeterol and fluticasone in the treatment of chronic obstructive pulmonary disease: a randomised controlled trial. Lancet. 2003;361(9356):449-56.

6. Fishman A, Martínez F, Naunheim K, Piantadosi S, Wise R, Ries A, et al. A randomized trial comparing lung-volume-reduction surgery with medical therapy for severe emphysema. N Engl J Med. 2003;348(21):2059-73.

7. Celli BR, Gote CG, Marin JM, Casanova C, Montes-de-Oca M, Mendez RA, et al. The body-mass index, airflow obstruction, dyspnea, and exercise capacity index in chronic obstructive pulmonary disease. N Engl J Med. 2004;350(10):1005-12.

8. Soler-Cataluña JJ, Martínez-García MA, Román Sánchez P, Salcedo E, Navarro $M$, Ochando $R$. Severe acute exacerbations and mortality in patients with chronic obstructive pulmonary disease. Thorax. 2005;60(11):925-31.

9. Calverley PM, Anderson JA, Celli B, Ferguson GT, Jenkins C, Jones PW, et al. Salmeterol and fluticasone proprionate and survival in chronic obstructive pulmonary disease. N Engl J Med. 2007;356(8):775-89.

10. Tashkin DP, Celli B, Senn S, Burkhart D, Kesten S, Menjoge S, et al. A 4-year trial of tiotropium in chronic obstructive pulmonary disease. N Engl J Med. 2008;359(15):1543-54.

11. Wedzicha JA, Calverley PM, Seemungal TA, Hagan G, Ansari Z, Stockley RA. The prevention of chronic obstructive pulmonary disease exacerbations by salmeterol/fluticasone proprionate or tiotropium bromide. Am J Respir Crit Care Med. 2008;177(1):19-26.

12. Hurst JR, Vestbo J, Anzueto A, Locantore N, Müllerova H, Tal-Singer R, et al. Susceptibility to exacerbation in chronic obstructive pulmonary disease. $\mathrm{N}$ Engl J Med. 2010;363(12):1128-38. 0
13. Agusti A, Calverley PM, Celli B, Coxson HO, Edwards LD, Lomas DA, et al. Characterization of COPD heterogeneity in the ECLIPS cohort. Respir Res. 2010;11(1):122.

14. Wedzicha JA. Choice of bronchodilator therapy for patients with COPD. N Engl J Med. 2011;364(12):1167-8.

15. Wedzicha JA, Decramer M, Ficker JH, Niewoehner DE, Sandström T, Taylor $\mathrm{AF}$, et al. Analysis of chronic obstructive pulmonary disease exacerbations with the dual bronchodilator QVA149 compared with glycopyrronium and tiotropium (SPARK): a randomised, double-blind, parallel-group study. Lancet Respir Med. 2013;1(3):199-209.

16. Wedzicha JA, Banerji D, Chapman KR, Vestbo J, Roche N, Ayers RT, et al. Indacaterol-glycopyrronium versus salmeterol-fluticasone for COPD. N Engl J Med. 2016;374(23):2222-34.

17. Magnussen H, Disse B, Rodriguez-Roisin R, Kirsten A, Watz H, Tetzlaff K, et al. Withdrawal of inhaled glucocorticoids and exacerbations of COPD. N Engl J Med. 2014;371(14):1285-94.

18. Fletcher C, Peto R. The natural history of chronic airflow obstruction. Br Med J. 1977;1(6077):1645-8.

19. Vestbo J, Anderson JA, Brook RD, Calverley PM, Celli BR, Crim C, et al. Fluticasone furoate and vilanterol and survival in chronic obstructive pulmonary disease with heightened cardiovascular risk (SUMMIT): a double-blind randomised controlled trial. Lancet. 2016;387(10030):1817-26.

20. Lipson DA, Barnhart F, Brealey N, Brooks J, Criner GJ, Day NC, et al. Oncedaily single-inhaler triple versus dual therapy in patients with COPD. N Engl J Med. 2018;378(18):1671-80.

21. Suissa S, Ariel A. Triple therapy trials in COPD: a precision medicine opportunity. Eur Respi J. 2018;52(6):1801848.

\section{CONFLICTS OF INTEREST}

The authors have no conflicts of interest to declare.

\section{CORRESPONDING AUTHOR}

António Duarte-de-Araújo

E-mail: duartearaujodr@sapo.pt

https://orcid.org/0000-0001-5811-3786

Recebido em 10-12-2019

Aceite para publicação em 07-02-2021

\section{RESUMO}

\section{COMO ALGUNS ENSAIOS CLÍNICOS RANDOMIZADOS INFLUENCIARAM A DECISÃO MÉDICA NA DPOC}

Os ensaios clínicos randomizados, juntamente com as revisões sistemáticas e meta-análises, têm sido o suporte da evidência em medicina. Alguns estudos, devido ao tamanho da amostra, ao uso de aleatorização, à participação de várias instituições ou ao longo follow-up, são capazes de fornecer um nível considerável de evidência. Descreve-se e comenta-se cronologicamente um grupo de trabalhos no âmbito da doença pulmonar obstrutiva crónica (DPOC) que influenciaram significativamente tanto a comunidade científica como a comunidade médica na compreensão e tratamento da doença, nos primeiros anos do século $\mathrm{XXI}$, e que por essa razão foram incorporados nas diferentes versões da estratégia GOLD.

Palavras-chave: DPOC; Evidência; Ensaios clínicos randomizados; Tratamento; Resultados. 